\title{
TEMEL MUHASEBE VARSAYIMLARI ve MUHASEBE POLITIKALARINA YÖN VEREN KAVRAMLAR
}

\author{
Cemal ÇAKICI \\ Marmara Üniversitesi, İ.̇̇.B.F., İsletme Bölümü, Yardımcı Doçent Dr.
}

\author{
Abstract: According to Turkish Accounting Standard-1: \\ Disclosure of Accounting Policies, fundamental assumptions \\ of accounting as follows: \\ I- Continuing-concern concert \\ 2- Consistency \\ 3- Matching principle \\ Also, the following considerations are important to select of \\ accounting policies: \\ I- Conservatism \\ 2- Substance over form \\ 3- Materiality \\ The aim of this study is to state above concepts as practical.
}

\section{GİRIŞ}

Uluslararası alanda muhasebe çalışmalarının iyileştirilmesi ve finansal tabloların güvenilir ve karşılaştırılabilir olması bakımından muhasebe standartları adı altında bir takım kurallar oluşturulmaktadır.

Bu kurallar öncelikle Uluslararası Muhasebe Standartları Kurulu (International Accounting Standards Committee-IASC) tarafindan oluşturulmakta ve daha sonra da üye ülkeler tarafindan uyum çalışmaları yapılmakta ve ulusal düzeyde muhasebe standartlanı yayımlanmaktadır. Şu anda IASC tarafindan oluşturulan 41 adet uluslararası muhasebe standardı bulunmaktadır [1].

Türkiye'de ise, 1994 yılında Türkiye Muhasebe ve Denetim Standartları Kurulu (TMUDESK) kurulmuş ve bugüne kadar 15 adet muhasebe standardı yayımlamıştır.

Bu çalışmada, 01 Ocak 1997 tarihinde yürürlüğe giren TMS-1: Muhasebe Politikalarının Açıklanması standard1 [2] kapsaminda yer alan temel muhasebe varsayımları ve muhasebe politikalarına yön veren kavramlara eleştirisel bir gözle bakılması ve uygulamalı bir şekilde açıklanması amaçlanmaktadır.

\section{TMS-1'IN KONUSU}

TMS-1, finansal tablolarm düzenlenmesinde ve incelenmesinde benimsenen temel muhasebe politikalarının açıklanması amacıyla oluşturulmuştur.
Finansal tablolar terimi bilanço, gelir tablosu, satışların maliyeti tablosu, nakit akış tablosu, öz kaynaklar đeğişim tablosu, kâr dağıtım tablosu ve bu tablolara ilişkin dipnot ve açıklamaları kapsamaktadır [3].

THP. açiklamalarına göre bilanço ve gelir tablosu dipnotları ve ekleri ile birlikte temel mali tabloları oluştururken diğerleri ise (satışların maliyeti tablosu, fon akım tablosu, nakit akım tablosu, kâr dağıtım tablosu ve öz kaynaklar değişim tablosu) ek mali tabloları oluşturmaktadır [4].

Ancak ek mali tabloları bütün mükelleflerin düzenlemeleri zorunlu değildir. MSUG.Tebliği Sura No: 10 'a göre, 2000 yılı aktif toplamı 1,8 trilyon lirayı veya net satışlar toplamı 4 trilyon lirayı aşan mükelleflerin temel mali tabloların yanı sira ek mali tabloları da düzenlemeleri zorunludur. Aynı tebliğe göre söz konusu mükelleflerin 2001 yllinda verecekleri yıllik gelir veya kurumlar vergisi beyannamesine ek mali tablolardan sadece kâr dağıtım tablosunu eklemeleri yeterli görülmưtştür. Her ne kadar beyannameye eklenmeseler de kriterleri aşan mükelleflerin kâr dağıtım tablosu dışında kalan ek mali tabloları da düzenlemeleri ve Türkiye Muhasebe Standartlarna dikkat etmeleri gerekmektedir [5].

\section{TEMEL MUHASEBE VARSAYIMLARI}

İşletmenin sürekliliği, tutarlılık ve tahakkuk esası kavramları temel muhasebe varsayımları olarak kabul edilmektedir. Yani normal şartlarda finansal tablolar düzenlenirken bu koşulların sağlandığı düşünülmekte olup bu koşullara uyulmaması istisnai bir durum olarak öngörillmekte ve böyle bir durumda gerekçeleri ile açıklama yapılması gerekmektedir [3]].

Oysa THP. kapsamma giren işletmeler için 12 tane temel muhasebe kavramı kabul edilmiştir. Bu standartta ise bunlardan sadece 3 tanesi temel muhasebe varsayım olarak öngörülmektedir. THP. . kavramlarına uymak zorunludur. Bunlara uyulmaması 2001 yllı için 850.000 .000 TL. ózel usulsüzluk cezasın gerektirmektedir [6]. 
concept) ise; işletmenin sürekliliği kavramı uyarmnca sınursiz kabul edilen ömrünün belli dönemlere bölünmesi ve her dönemin faaliyet sonuçlarının diğer dönemlerden bağımsız olarak saptanmasıdır [7]. Bu kavram gereğince ortaya çıkan muhasebe dönemi ise genellikle 1 yldır ve 01 Ocak tarihinde başlayıp 31 Aralık tarihinde sona ermektedir.

Gelir ve giderlerin tahakkuk esasina göre muhasebeleştirilmesi, hasılat, gelir ve kârların aynı döneme ait maliyet, gider ve zararlarla karşılaştırilması bu kavramın geregidir.

$\mathrm{Bu}$ kavramin işletmeler açısından geçerliliğinin bulunmadığı veya ortadan kalktığı durumlarda ise, bu husus mali tabloların dipnotlarında açıklanır [4].

Dönemsellik kavramı, süreklilik kavramına ters düş̧iyormuş gibi görünse de gerçekte böyle bir şey yoktur. İșletmenin ömrünün sonsuza dek süreceğini varsaymakla faaliyet sonuçların belli bir dönemi esas alarak değerlendirmek, biçimsel açıdan farklı görünse de özde birbirini tamamlayan olgulardır. Süreklilik kavramını bir zincir olarak kabul edersek, bu zincirdeki her halka bağımsız bir dönemi ifade eder. Tek tek halkaların varlığı zincirin varlığına ters düşmeyeceği gibi dönemsellik ilkesi de süreklilik ilkesine ters düşmez. Ayrıca, faaliyetini sonsuza dek sürdüreceği varsayılan bir işletmenin başarı ya da başarısızlığını olçebilmek de ancak belli dönemler itibariyle almnacak sonuçların karşılaştırılmasiyla olasıidır [9].

Vergi kanunlarında da dönemselliği öngören hükümler bulunmaktadır. Özellikle VUK. madde $174^{\prime}$ de defterlerin hesap dönemi itibariyle tutulacağı, kayıtların her hesap dönemi sonunda kapatılacağı ve ertesi hesap dönemi başında yeniden açulacağı belirtilmektedir. Maddenin devaminda hesap döneminin normal olarak takvim yılı olduğu hükme bağlanmış ve bunun istisnalarına yer verilmiştir. Diğer taraftan mükelleflerin işletmeye ait kıymetleri her hesap döneminin son gününde degerlemeye tabi tutmaları dönemsellik ilkesinin bir sonucudur. Özellikle aktif ve pasif geçici hesap klymetlerinin değerlemesine ilişkin 283 ve 287 . maddelerde dönemsellik ilkesi daha çok öne çımaktadır. Belirtilen maddeler uyarınca gelecek hesap dönemlerine ait olarak peşin ödenen giderlerle tahsil edilen hasılat ve cari hesap dönemine ait olup da henüz tahsil edilmemiş hasılatla henüz ödenmemiş giderler mukayyet değerleri üzerinden bilançoya aktarllırlar. Böylece bir dönemin gelir ve gideri diğer dönemin gelir ve giderinden ayrılmış ve dönemsellik kavramı korunmuş olmaktadır. BununIa birlikte vergi kanunlarında dönemsellik kavramına aykırı durumlar, yani dönemsellik kavramından sapmalar da mevcuttur. Bu durumlar aşağıda siralandığı gibidir [16]:

1. İșe başlama ve iși bırakma

2- Özel hesap dönemine geçiş

3- Faaliyetin durdurulmas1

4- Adi ortaklıkta ortaklarda değişiklik
5- Kollektif ve komandit şirketlerde ortak değişikliği

6- Ölüm ve memleketi terk

7. Münferit beyanname ile bildirilen gelirlerin vergilendirilmesi

8- Tevkif usulüyle vergileme

9- Tasfiye, birleşme ve devir

10- Mal ithalinde KDV uygulaması

Örnek.3: 01.10 .2000 tarihinde $1.000 .000 .000 \mathrm{TL}$. yatırilmak suretiyle 1 yll vadeli mevduat hesabı açtırılmıştır. Faiz oranı $\% 90$, Gelir Vergisi Stopaj oranı $\% 16$ ve fon payı $\% 10$ 'dur.

Tahakkuk esasina göre işletmenin 31.12.2000 tarihi itibariyle 01.10-31.12.2000 dönemine ilişkin faiz gelirini tahakkuk ettirmesi gerekmektedir. Buna göre 31.12.2000 tarihinde hesaplanan faiz tutarı ve yapılması gereken kayıt şöyledir:

Faiz tutarı $=(1.000 .000 .000 \times 90 \times 92 / 36.500)=$ $227.000 .000 \mathrm{TL}$. 31.12 .2000

181 GELIR TAHAKKUKLARI 227.000 .000

642 FAIZ GELIRLERI 227.000 .000

01.10.2000-31.12.2000 dönemi faiz gelirleri tahakkuku

30.09.2001 tarihine gelindiginde hesabın vadesi dolduğu için gelir gerçekleşmiş olmaktadır. Bu durumda yapılması gereken kayıt şöyledir: 30.09 .2001

102 BANKALAR

741.600 .000

193 PEŞIN ÖD. VERGI VE FON. $\quad 158.400 .000$
- Gelir Vergisi Stopaji $\quad 144.000 .000$
- Fon Pay1
14.400 .000
181 GELIR TAHAKKUKLARI
227.000 .000
642 FAİZ GELİRLERİ
673.000 .000

\subsubsection{1-30.09.2001 dönemi faiz tahakkuku}

Faiz Tutarl $=1.000 .000 .000 \times \% 90=900.000 .000$

Gelir Vergisi Stopaj $1=900.000 .000 \times \% 16=144.000 .000$

Fon Pay $1=144.000 .000 \times 10=14.400 .000$

Bu noktada tahakkuk esası ile ihtiyatlılı kavramı çelişiyormuş gibi görünse bile aslında bir çelişki yoktur. Çünku tahakkuk ettirilen gider ve gelirlerde bir belirlilik, yani kesinlik olmasına rağmen, ihtiyatllilk kavramında ele alınan gider ve gelirlerde bir belirsizlik söz konusudur. Giderler için de benzer bir uygulama geliştirilebilir. 
Örnek.4: İşletme faaliyette bulunduğu bina için 3 yıllık kira bedelini peşin olarak ödemiştir. Kira tutarı aylık 500.000.000 TL.'dan 3 ylllı 18.000.000.000 TL.'dır. Gelir Vergisi stopaj oranı \%20, Fon Payı oranı \%10'dur. 01.01.2001 tarihi itibariyle anlaşma ve ödeme yapıldığını düşünürsek şöyle kaydedilmelidir:

\subsection{1 .2001}

280 GELECEK YILL. AIT GID.

12.000 .000 .000

180 GELECEK AYL. AİT GID.

6.000 .000 .000

$100 \mathrm{KASA}$

14.040 .000 .000

360 ÖD. VERGI VE FON.

3.960 .000 .000

- Gelir Vergisi 3.600 .000 .000

- Fon Payı $\quad 360.000 .000$

3 yllik kira ödemesi nedeniyle.

Bundan sonra 2001 yllı için her ay sonu itibariyle aşağıdaki kayıt yapılmalıdır (7/A seçeneğine göre):

770 GENEL YÖNETIM GID. $\quad 500.000 .000$

180 GELECEK AYL. AIIT GID. $\quad 500.000 .000$

2001 yll ...... ayı kira tahakkuku. şöyledir:

2001 y1lı sonunda yapilmasi gereken kayit

$$
\text { 31.12.2001 }
$$

180 GELECEK AYL. AIT GID. $\quad 6.000 .000 .000$

280 GELECEK YILL. AİT GID. $\quad 6.000 .000 .000$

2002 ytl kira bedellerinin belirlenmesi nedeniyle

Vergisel açıdan gelirin tahakkuk etmesi de farklı olmaktadır. Özellikle bu konu menkul kıymet faiz gelirleri bakımundan önem arz etmektedir. Şöyle ki; menkul klymet faiz gelirleri belli bir vadeye bağlı olduğu takdirde, vadenin gelmesiyle bu gelire hak kazanılır. Vade gelmeden faiz gelirlerinin tahakkuk etmesinden bahsedilemez. Menkul kıymet iktisap edildiğinde, vadesi geldiğinde ne kadar gelir elde edileceği bilinmekle birlikte, bu süre geçmeden bu gelire hak kazanılması da mümkün değildir. Bu itibarla menkul sermaye iratlarında elde etme, hukuki ve ekonomik tasarrufa bağlanmıştır. Diğer bir ifadeyle, tahakkuk eden bir gelirin talep edilebilir safhaya gelmesi yeterli değildir; gelirin sahibinin emrine amade kılınması da gereklidir. $\mathrm{Bu}$ ișlem hangi hesap döneminde gerçekleşmişse, tahsil edilme işlemi daha sonraki bir dönemde gerçekleşmiş olsa bile bu hesap döneminin geliri olarak vergilendirilir. Bu halde dahi, gelirin elde edilmesinin tahsil esasına bağlandığı ileri sürülemez.

Menkul k1ymet faiz gelirlerinin ticari faaliyete bağlı olarak elde edilmesinde ise, tahakkuk esasının geçerli olaçağında kuşku yoktur. Ancak tahakkuk esasını, dönemsellik kavramı ile karıştırmak, aktif veya pasif geçici hesap kıymetlerinin bir unsuru görmek doğru bir yaklaşım şekli değildir. Dolayısıyla menkul kıymet faiz gelirleri, menkul kıymetin vadeli olması halinde, vadenin gelmesiyle tahakkuk eder. Bunun böyle olmasinda da, menkul klymetin bir sermayeyi temsil etmesinin önemi büyüktür [17].

\section{MUHASEBE POLITTIKALARINA YÖN VEREN KAVRAMLAR}

İhtiyatılılı, özün önceliği ve önemlilik temel kavramları muhasebe politikalarının seçimi ve uygulanmasını yönlendirir [3]. Yani yukarıdaki kavramlara dayanılarak farklı yöntemler uygulanabilir.

\section{A. İhtiyatllık Kavramı}

Ihtiyatlllk (conservatizm) kavramı, muhasebe olaylarında temkinli davranılması ve işletmenin karşılaşabileceği risklerin göz önüne alınması gereğini ifade eder [3]. Bu kavramın sonucu olarak, işletmeler, muhtemel giderleri ve zararları için karşılık ayırırlar, muhtemel gelir ve kârları için ise gerçekleşme dönemlerine kadar herhangi bir muhasebe işlemi yapmazlar [7]. Buna göre gerçekleşmemiş bir zarar mutlaka kaydedilmelidir ancak gerçekleşmemiş bir kâr asla kaydedilmemelidir [9]. Ancak bu kavram gizli yedekler veya gereğinden fazla karşılık ayrılmasına gerekçe oluşturmaz.

Dikkat edilecek olursa ihtiyatlılk kavramı tanımında muhtemel gider ve zararlar ile muhtemel gelir ve kârlar denilmektedir. Burada geçen muhtemel kelimesi kavramın özünü teşkil etmektedir. Muhtemel kelimesi bir bakıma olması olası olan şey ya da gerçekleşeceği tam kesin olmayan şey anlamına gelmektedir. Bu nedenle bir kesinlik yoktur, bir belirsizlik vardır ve belirsizliklerin çoğu ișlemleri etkilemesi kaçınılmazdır [18]. Zaten bir kesinlik olsaydı o zaman tahakkuk esasına göre giderlerin ve gelirierin tahakkuk ettirilmesi gerekirdi.

Muhtemel gider ve zararlar neler olabilir?

Tanımdan da anlaşılacağı üzere karşılık ayrılmasını gerektiren bütün olaylar muhtemel gider ve zarar kapsamına girmektedir. Şöyle ki (THP. gereğince):

- Menkul Kıymetler Değer Dưşüklügüu

- Şüpheli Ticari Alacaklar

- Stok Deger Düşüklüğü

- Diğer Dönen Varlıklar Iç̧in Sayım Noksanlığı

- Bağlı Menkul Kıymetler Değer Düşüklüğü 
- Diğer Mali Duran Varlıklar Değer Düşüklüğü

- Kıdem Tazminatları

Muhtemel gelir ve kâra sebep olacak konular ise yukarıdaki unsurların tam tersi yani değer artışları olabilir. Örneğin; menkul kıymetler değer artışı gibi. İhtiyatlılık ilkesi gereğince menkul kıymetler değer artışı için gerçekleşme anına kadar herhangi bir kayıt yapilmamalıdır. Ayrıca, hisse senetlerindeki "borsa rayici" ile değerleme ölçüsü, muhasebenin temel kavramlarmdan "ihtiyatlllı kavramı" ile bağdaşmamaktadır. Tahakkuk etmeyen, gerçekleşmeyen bir gelirin gelir olarak kaydedilmesinin genel kabul görmüș muhasebe ilkelerine aykırı olduğu açıtır. Özellikle spekülásyona dayalı olarak dalgalanmaların çok yüksek olduğu borsalarda hisse senetlerindeki değer değişmelerinden kaynaklanan artışların gelir olarak kayıtlara yansıtılması ticaret hukuku ilkelerine ters düştüğü gibi, değerleme gününden potansiyel gelir olarak ortaya çıkan unsurların kâr dağıtımına konu yapılarak işletme dışına aktarılmasını da sağladığından, doğru bir yaklaşım şekli değildir [17].

Örnek.5: Alacak senetlerinden 500.000.000 TL.'llk kısmi vadesinde ödenmediği için protesto olmuştur. Protestoya rağmen de ödenmedikleri için icraya verilmiştir. Bu durumda intiyatlllık ilkesi geregince yapılması gereken kayıtlar şöyledir:

121 ALACAK SENETLERI
121.02 Protestolu Senetler
121 ALACAK SENETLERI
121.01 Portföydeki Senetler
Alacak senetlerinin protesto olmast

121 ALACAK SENETLERİ
121.03 İcraya Verilen Senetler
121 ALACAK SENETLERİ
121.02 Protestolu Senetler
Alacak senetlerinin icroya verilmesi.

\begin{tabular}{cc}
\hline & \multicolumn{1}{c}{$/$} \\
128 SÜPHELİ TIC. ALACAKLAR & 500.000 .000 \\
121 ALACAK SENETLERİ & 500.000 .000 \\
121.03 İcraya Verilen Senetler & \\
Süpheli alacaklarin belirlenmesi. &
\end{tabular}

Supheli alacaklarin belirlenmesi.

654 KARŞILIK GIDERLERİ

500.000 .000

129 ŞÜPHELİ TİC. ALAC. KARŞ. $\quad 500.000 .000$ Süuheli alacaklar için karşlllk ayrtlmast.

\section{B. Özün Önceliği Kavramı}

Özün önceliği (substance over form) [19] kavramı, işlemlerin muhasebeye yansıtılmasında ve onlara iliş̧in değerlendirmeler yapılmasında biçimlerinden çok özlerinin esas alınması gereğini ifade eder. Genel olarak işlemlerin biçimleri ile özleri paralel olmakla birlikte bazı durumlarda farklılıklar ortaya çıkabilir. Bu takdirde özün biçime önceliği esastır [3].

Bu konuda çek örneği verilebilir. Ticaret Kanunu geregince (mad. 707) çekte vade yoktur. Yani ibraz edildiği anda ödenir. Ancak uygulamada çekłere vade yazıldığı çok sık görülen bir durumdur. Böyle üzerine vade yazılmış olan çekler, özün önceliọi kavramı gereğince artık çek olarak değil de senet olarak dikkate alınmalı ve muhasebeleştirilmelidir [9].

Bu konuda 10 günlük bir süre genel kabul görmüştür. TTK. madde 708'e göre bir çek keşide edildiği yerde ödenecekse on gün; keşide edildiği yerden başka bir yerde ödenecekse bir ay içinde muhataba ibraz edilmelidir [20]. Bu nedenle vade 10 güne kadar ise Alınan Cekler hesabına 10 günden fazla ise Alacak Senetleri hesabına kaydedilmelidir. Verilen çekler durumunda ise borç senetleri hesabı kullanılmalidır. Bu durumda ilgili senet hesapları altında çek ve senetleri ayırmak amacıyla alt hesap düzenlemesi yapılabilir.

Örnek.6: Satıcı (A) İşletmesi'ne olan 180.000.000 TL.'llk borca karşılık 1 ay vadeli çek verilmiştir. Özün önceliği kavramı gereğince, ilgili çek vadeli, yani 10 günden daha fazla vadeli olduğu için kayıtların aşağıdaki gibi yapılması gerekmektedir:

\section{SATICILAR}

180.000 .000

320.01 (A) İşletmesi

321 BORÇ SENETLERİ

180.000 .000

321.02 Vadeli Çekler

1 ay vadeli çek verilmesi.

Verilen çekin vadesine 10 gün kaldığı zaman aşağıdaki kayıt yapılmalıdır:

\section{BORÇ SENETLERİ}

180.000 .000

321.02 Vadeli Çekler

103 VERIL. ÇEK. VE ÖD. EMİR. $\quad 180.000 .000$

Vadeli çekin ilgili hesaba aktarlması.

Çekin vadesi gelip de, satıct tarafindan bedelinin bankadan çekilmesi üzerine așağıdaki kayıt yapılmalıdır:

\begin{tabular}{cc}
\hline 103 VERIL. CEK. VE ÖD. EMİR. & 180.000 .000 \\
102 BANKALAR & 180.000 .000
\end{tabular}

Çek bedelinin bankadan ödenmesi nedeniyle. 


\section{C. Önemlilik Kavramı}

Önemlilik (materiality) kavramı, bir hesap kalemi veya finansal bir olayın nispi ağırlık ve değerinin, finansal tablolara dayanılarak yapılacak değerlemeleri veya alınacak kararları etkileyebilecek düzeyde olmasını ifade eder [12].

Önemli hesap kalemleri, finansal olaylar ve diğer hususların finansal tablolarda yer almasi zorunludur [3].

Önemlilik kolayca anlaşılır bir kavram değildir. Belli bir ölçüsü ve standardı yoktur. Bir işletmeci yönünden önemli olan bir unsur bir başkası yönünden önemsiz kabul edilebilir. Yine de bu konuda iki ölçütten söz edilebilir:

\section{- Miktarın oransal büyüklüğu}

- Miktarın üçüncü şahıslar için önemi

Miktarın oransal büyüklüğü, kuşkusuz ilgili kalemin parasal mutlak değeri ile birlikte ele alındığında anlam kazanır. Örneğin; \%10 oranı tek başına önemli bir orandır. Ancak bu oran $50.000 \mathrm{TL}$. için ayrı anlam, 50.000.000 TL. için ayrı anlam ifade eder. Ayrıca, bir unsurun önemliliği 0 unsurun bilinmesinin, yönetimin, ortakların, alacaklıların ve benzerlerinin kararlarına etkili olacağına dair bir neden olması halinde söz konusu olacaktır [9].

Bu konuda da örnek olarak amortismana tabi duran varlıklar verilebilir. VUK. (mad. 313) gereğince amortismana tabi iktisadi kıymetler için bir sınır getirilmiștir. Buna göre 2001 yilı için 150.000 .000 lirayı aşmayan peştemallıklar ile işletmede kullanılan ve değeri 150.000.000 lirayı aşmayan alet, edavat, mefruşat ve demirbașlar amortismana tabi tutulmayarak doğrudan dogruya gider yazılabilir [21]. Bu itibarla bu tutarın altında bir değeri olan duran varlıklar uzun yillar kullanılacak olsalar dahi önemsiz kabul edilip doğrudan gider yazılabilirler.

Böylece önemlilik kavramı gereğince kalem, cetvel, çöp sepeti vb. gibi küçük araçların tutarı önemsiz kabul edilmekte ve amortisman ayırmak yerine doğrudan gider yazilmasina izin verilmektedir [22].

Örnek.7: İșletmenin yönetim bölümünde kullanılmak üzere 5.000 .000 TL.'na bir kalemlik satın alınmıştır. Ayrıca, 900.000 TL. KDV. ödenmiştir.

\begin{tabular}{lr}
770 GENEL YÖNETIM GID. & 5.000 .000 \\
191 İNDIRILECEK KDV. & 900.000 \\
100 KASA & 5.900 .000 \\
... nolu fatura ile satm alman kalemlik. & \\
\hline
\end{tabular}

Denetim açısından bakıldığında önemliliğin ölçülmesinde hangi ölçütlerden hareket edileceği hakkında kesin bir şey söylemek çok zordur. Bununla birlikte yapilan bir araşturmaya göre, denetçilerin önemlilik konusunda karar alırken aşağıdaki değiş̧kenlere başvurdukları saptanmıştır:

- İlgili kalemin türü

- İlgili kalemin cari yıl net kârına oranı

- Ilgili kalemin toplam hasilata veya giderlere oranı

- İgili kalemin net çalıșma sermayesi üzerine yapacağı etki

- Kazançların büyüme hızı

- İlgili kalemin kazançların yükselme eğilimini ters yönde etkileyip, etkilemedigi

- İlgili kalemin mutlak (vergi etkisinden arındırımış) tutarı

- Hisse senetleri fiyatna olacak etkisi

$\mathrm{Bu}$ araştırma sonuçlarına bakarak denetçilerin önemliliği saptamada kararlarını daha ziyada sayısal değişkenlere dayandırdıklarını söyleyebiliriz. Çünkü yukarıda sayılan değişkenler ile ilgili kalemin finansal tablolar üzerine yaptığı sayısal etki ölçülmeye çalışılmaktadır. Buna göre denetçi, örneğin, gelir tablosu açısından bir kalemin önemliliğini araştırmaktaysa, o kalem tutarının faaliyet dönemi net karına oranını saptayacak ve bu orana göre kalemin önemli olup olmadığına karar verecektir. Denetim uygulamasında yerleşmiş bir kurala göre, bir tutar net kârın \% 10 'undan fazla ise önemli, \% 5 'inden az ise önemsiz sayılmaktadir. Denetçi bu sınırları dikkate alarak koşullara göre bir kalemin önemli olup olmadığına karar verir [23].

\section{v. SONUÇ}

Temel muhasebe varsayımları olarak kabul edilen işletmenin sürekliliği, tutarlılık ve tahakkuk esası (dönemsellik) ile muhasebe politikalarma yön veren ihtiyatılıtk, özün önceliği ve önemlilik kavramları TMS-1: Muhasebe Politikalarının Açılanması standardı kapsamında yer aldığı gibi Muhasebe Sistemi Uygulama Genel Tebliği'nde de bu kavramlara ilişkin açıklamalar bulunmaktadir.

Süreklilik kavramı gereğince, işletmenin gerçek kâr ya da zararı ancak ișletmenin tasfiyesi ile ortaya çıkmakta olup, dönemler itibariyle elde edilen kâr ya da zarar rakamları tam olarak gerçeği yansıtmamaktadır.

Finansal tablolardan karșılaștıılabilir bilgiler alınabilmesi bakımından tutarlılık kavramına uyulmalı ve dönemler itibariyle uygulanan muhasebe politikaları değiştirilmemelidir. 
Her ne kadar işletmenin faaliyetleri sonsuza kadar sürse bile tahakkuk esası (dönemsellik) kavramı gereğince her dönemin gelir ve giderlerinin karşılaştırılması ve sonuçlarının bulunması gerekmektedir.

İhtiyatllık kavramına göre işletmeler muhtemel gider ve zararları için karşılık ayırmalı, muhtemel gelir ve kârları için ise gerçekleşme anına kadar herhangi bir kayıt yapmamalıdır.

Ayrıca, finansal tabloların gerçeği yansitması bakımından, çek ömeğinde olduğu gibi işlemlerin kaydedilmesinde biçimlerinden çok özlerine dikkat edilmeli yani özün önceliği kavramına uyulmalıdır.

Önemlilik kavramı gereğince ise, sonuçlar üzerinde önemli etkiler yaratmayacak kadar küçük rakamların üzerinde durulmaması ve pratik bir şekilde kaydedilmeleri öngörülmektedir.

\section{YARARLANILAN KAYNAKLAR}

[1] -..----, www.iasc.org.uk

[2] -------, TMUDESK - Türkiye $\begin{gathered}\text { Muhasebe ve } \\ \text { Denetim Standartları Kurulu: Türkiye Muhasebe }\end{gathered}$ Standartları 1997, Türmob Yayın No: 32, Ankara 1997, s.13.

[3] -......, TMS-1, mad. 1-2, 3, 8/a, 8/b, 8/c, 4, 10/a, 10/b, $10 / \mathrm{c}$.

[4] ------, MSUGT. Sira No: 1.

[5] -------, MSUGT. Sira No: 10.

[6] ------, VUK. mad. 353/6, mük.mad.320.

[7] LARSON / PYLE, Fundamental Accounting Principles, Eleventh Edition, Irwin, 1998, s.16, 87, 80, 331 .

[8] ATAMAN, Ümit; HACIRÜSTEMOĞLU, Rüstem; BOZKURT, Nejat, Muhasebe Denetimi Uygulamaları, Alfa Yayınları, İstanbul 2001, s. 182.

[9] ----.--, MALIYYE HESAP UZMANLARI DERNEĞİ, Denetim İlke ve Esasları, İstanbul 1999, s.331, 509-511.

[10] AKDOĞAN, N.; TENKER, N., Finansal Tablolar ve Mali Analiz Teknikleri, Gazi Kitabèvi, Ankara, 2001, s.39.

[11] YAZICI, Mehmet, Muhasebe Tümlemleri ve Örgütlenmesi, İkinci Baskı, MÜ.N.S. Yayın ve Yardım Vakfi Yayin No: 522/756, İstanbul 1998, s.28.

[12] HILLMAN; KOCHANEK; REYNOLDS, Principles of Accounting, Fifth Edition, Dryden, USA, 1990, s.630, 631.

[13] SMITH, J.L.; KEITH, R.M., Accounting For Financial Statement Presentation, McGraw-Hill Inc., USA. 1979, s.33.

[14] WELSCH, G.A.; CHESLEY, G.R., Fundamentals of Financial Accounting, Irwin Inc, USA 1990, s.155.
[15] BERNEY, P.R.; LYONS, W.P.; GARSTKA, S.J., Financial Accounting And Reporting-Text And Cases, Business Publications, Inc., USA. 1981, s.75.

[16] DURGUN, Ercan, "Vergi Kanunlarmda Dönemsellik İlkesi ve İstisnaları", Vergi Dünyası, Sayı: 220, Aralık 1999.

[17] ARSLAN, Erdoğan, "İşletme Aktifine Kayltlı Hazine Bonosu ve Devlet Tahvil Faizlerinin Elde Etme Zamanı ve Tahakkuk Esası", Vergi Dünyası, Sayı:184, Aralık 1996.

[18] DURMUŞ, A. H., Uluslararası Muhasebe Standartları (1-31), İstanbul, 1992, s.13.

[19] \$NSOY, Necdet, Selected Topics On Turkish Tax Accounting, Istanbul 1994, s. 126.

[20] TEKINALP, Ü.; ÇAMOĞLU, E., Açıklamalı, Notlu ve Karşılaştırmalı Türk Ticaret Kanunu, Yedinci Bası, Beta Basım Yayım Dağıtım AŞ., Ístanbul 1992, s.326.

[21] DOĞRUSÖZ, Bumin A., Temel Vergi Kanunları, Lebib Yalkın Yayınları AŞ., İstanbul 2000, s.442.

[22] WALGENBACH, P. H.; DITTRICH, N. E.; HANSON, E.I., Financial Accounting, Second Edition, Harcourt Brace Jovanovich Inc, USA. 1977, s.426.

[23] KAÇAR, Yusuf, "Muhasebe ve Vergi Denetiminde Önemlilik", Vergi Dünyası, Sayı:214, Haziran 1999. 